\title{
Knowledge production in Iranian social determinants of health research centers: Toward health equity
}

\author{
Katayoun Falahat ${ }^{1}$, Monir Baradaran Eftekhari*1(D), Asghar Ebadifar ${ }^{1,2}$, Masoumeh Eltemasi ${ }^{1}$, Zahra Sobhani ${ }^{1}$, \\ Elham Ghalenoee ${ }^{1}$, Elham Habibi ${ }^{1}$
}

Received: 3 Aug 2019

Published: 6 Jun 2020

\section{Abstract}

Background: As the partner country of the WHO Commission on Social Determinants of Health (SDH), Iran has expanded the knowledge based on the social determinants of health- as one of commission recommendations- by establishing SDH research centers to collect evidence and design responses to the existing health equity gap. Considering the importance of the role assigned to these research centers, this study aimed to present the knowledge production of SDH research centers and determine their status in Iran's health research system (HRS).

Methods: In this cross sectional study, research performance of SDH research centers was assessed based on international research indicators and compared with national medical research centers and HRS knowledge production. Then, SDH research centers were scored and ranked based on the research indicators.

Results: Out of 37 approved SDH research centers, the knowledge performance of 33 research centers was reviewed. The total number of academic members was 334. The number of these centers' indexed published articles and the proportion of published articles per academic member have been doubled from 483 and 1.44 in 2015 to 984 and 2.94 in 2017. In this period, the number of citations of the past 5-year publications was 4355 according to Scopus database. The proportions of these centers' high-quality publication (Q1) and international collaborations per published articles were 14.8 and 8.25. In ranking, the first to third ranks were occupied by SDH research centers of Kermanshah, Kurdistan, and Qazvin Universities of Medical Sciences.

Conclusion: Although knowledge production seems desirable in mentioned research centers, it is essential to create a virtual research network to increase intersectoral collaboration and develop strategies to solve the puzzle of gathering evidence on the social determinants affecting health inequities.

Keywords: Health equity, Social determinants of health, Health research system, Research center, Knowledge production, Iran

Conflicts of Interest: None declared

Funding: This program was supported by the Ministry of Health and Medical Education, Deputy of Research and Technology, Islamic Republic of Iran.

\section{*This work has been published under CC BY-NC-SA 1.0 license.}

Copyright $\odot$ Iran University of Medical Sciences

Cite this article as: Falahat K, Baradaran Eftekhari M, Ebadifar A, Eltemasi M, Sobhani Z, Ghalenoee E, Habibi E. Knowledge production in Iranian social determinants of health research centers: Toward health equity. Med J Islam Repub Iran. 2020 (6 Jun);34:58. https://doi.org/10.47176/mjiri.34.58

\section{Introduction}

Equity in health is an important priority, and equitable

Corresponding author: Dr Monir Baradaran Eftekhari, mbeftekhari200@gmail.com

1. Deputy for Research and Technology, Ministry of Health and Medical Education, Tehran, Iran

2. Dentofacial Deformities Research Center, Research Institute of Dental Sciences, Department of Orthodontics, Dental School, Shahid Beheshti University of Medical Sciences, Tehran, Iran access to health care has been cited as the crucial responsi-

$\uparrow$ What is "already known" in this topic:

Although there are 37 approved social determinants of health research centers in Iran, no study has been conducted on knowledge production assessment in these research centers.

\section{$\rightarrow$ What this article adds:}

According to this study, although the trend of knowledge production of social determinants of health research centers is increasing, in terms of quality of knowledge production (the number of indexed articles in ISI, high quality publication, citation, and international collaboration), these research centers are lower than average compared to all medical research centers, and more efforts should be made to improve the quality of research in these research centers. 
bility of governments and policymakers of all developed and developing countries to achieve many of the Millennium Development Goals (MGD) $(1,2)$. Based on the definition of health, which comprises the psychological, spiritual, social, and physical dimensions, a wide range of factors affect its equity (3). Many studies suggest that health inequities, which include differences in the presence of diseases, health outcomes, or access to health car e, are largely affected by disparities of gender, race, ethnicity, socioeconomic status, etc., collectively as social determinants of health $(\mathrm{SDH})$ between and within population $(4,5)$. SDH" the social conditions in which people are born, grow up, live, work, and cross different stages of life" are shaped by social, political, and economic forces. These determinants, as the most powerful drivers of health equity, influence people's opportunities for accessing resources and power (Fig. 1) $(6,7)$.

The World Health Organization (WHO) considers health inequity by paying attention to the SDH as the cause of health inequities and disparities (7). In 2005, the WHO Commission on Social Determinants of Health $(\mathrm{CSDH})$, was established as a global network, called policymakers, researchers, civil society, as well as national and international organizations to tackle the social causes of poor health and avoidable health inequalities $(2,8)$. The major recommendations for action of the Commission were to improve living conditions, reduce the inequitable distribution of money, power and resources for healthy life, and expand the knowledge through monitoring, research, and training (9). In this regard, one of actionable strategies of CSDH to achieve its goals was encouraging partner countries to generate knowledge, gather and review evidence, and research on effective policies and intervention considering disparities of SDH and health inequities within and between countries (10).

In 2005, Iran was also selected as the CSDH partnership country to tackle inequity and adopt an SDH approach in national health system according to its valuable and applicable experiences in developing and implementing the
Primary HealthCare (PHC) system (11). Later, to institutionalize this approach, the Iranian Ministry of Health and Medical Education (MoHME) defined the national indicators for equity in health and developed the tools for monitoring and evaluating them. Additionally, in 2010, this approach was emphasized as a national priority in the policies, programs, and activities of Iranian universities of medical sciences (UMSs) (12). One of the most outstanding national action plans was the establishment of Social Determinants of Health Research Centers (SDHRC) in each UMS research structure $(12,13)$. Aligned with CSDH recommendations, SDHRC, defined as one of the efficient research bodies, can implement interdisciplinary and multidisciplinary research and generate evidence on extremely wide range of SDH based on their specific priorities to indicate the context-dependent underlying causes of health inequity such as culture and political policies and the best intervention to reduce the equity gap (5).

MoHME facilitated the process of establishing SDHRC and, to date, about 37 SDHRCs have been approved all over the country (14). These research centers operate under the supervision of SDH Secretariat of Social Affair Department of MoHME (11) and are evaluated annually (15).

Considering the existing challenges of SDH domain in the country (16) and the strategic role of these centers in Iran's health research system (HRS), and despite their annual evaluation, lack of enough evidence on their knowledge production and national situation, this study aimed to present the knowledge production of SDHRCs and determine their status in Iran's HRS. Results of this study can serve as a resource for policymakers and researchers to enhance interventions on the SDH and health equity in health-related or nonhealth-related sectors.

\section{Methods}

\section{Setting}

The present survey took place in I.R of Iran. In 2017, Iran had 56 governmental universities of medical sciences

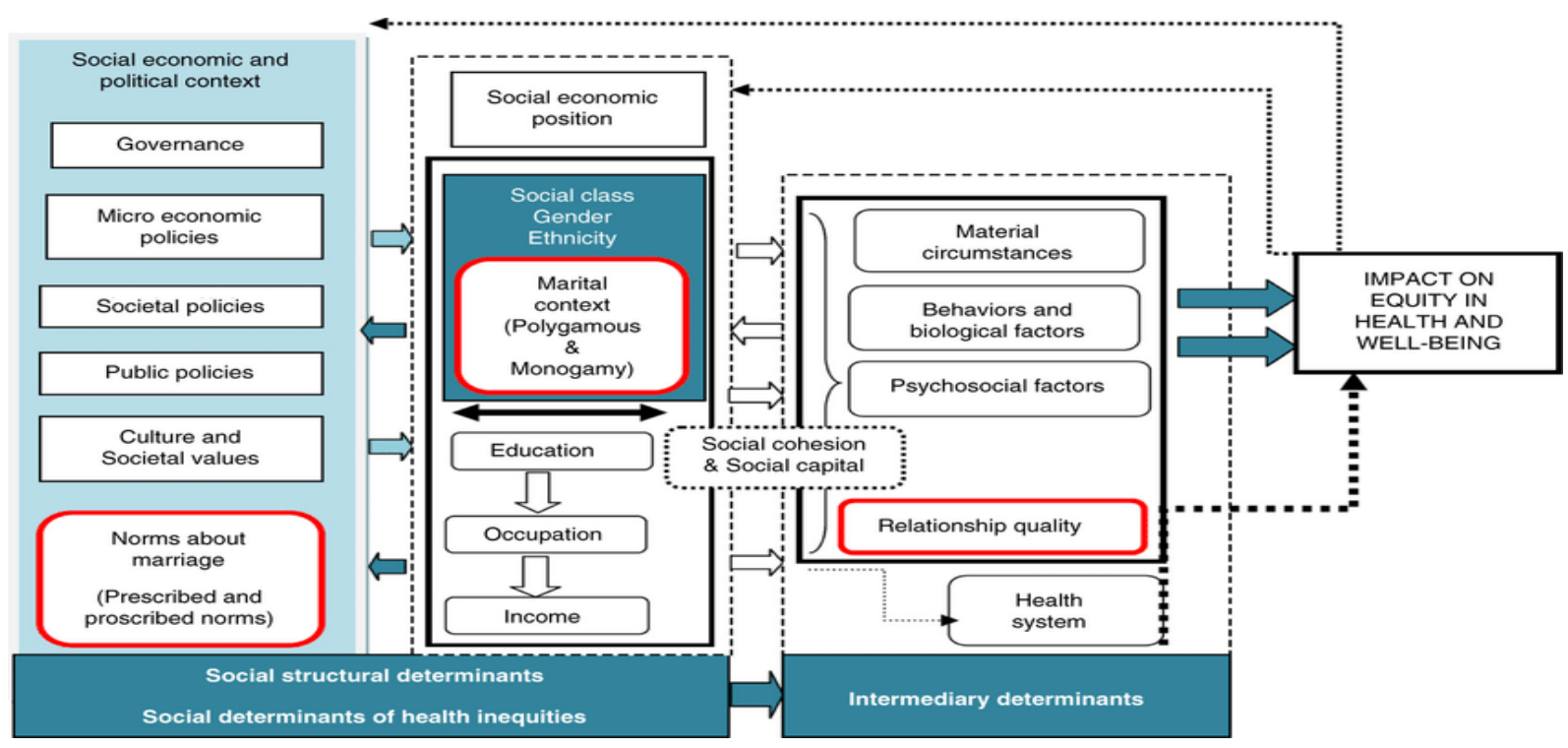

Fig. 1. WHO Social Determinants of Health Framework 
and 725 approved medical research centers (MRCs). All MRCs are approved by Development Council of Universities of Medical Sciences in the MOHME. The research activities of approved MRCs are evaluated annually by the Undersecretary for Research and Technology of MoHME via the national medical research evaluation system (17, 18). This evaluation is performed in a quantitative manner based on international scientific indicators, significantly enhancing the quality and quantity of studies and researches in national HRS (19). In the present study, SDHRC is defined as MRC in the domain of SDH and equity in health.

\section{Study design}

This was a cross sectional study conducted in the winter of 2018 based on the evaluation results of knowledge production in MRCs and UMSs in I.R of Iran. The research population comprised all approved SDHRCs by Development Council of Universities of Medical Sciences in the MOHME. The sample included all active SDHRCs with at least 3 years of official research activity and active participation in the MRCs research evaluation.

The knowledge production of SDHRCs was investigated based on the existing evaluation reports of MRCs research performance in years 2015, 2016, and 2017. These reports were retrieved from the website of the Undersecretary for Research and Technology of MoHME (14). In the evaluation process, all MRCs knowledge production were evaluated and scored based on international research indicators (20-22) and ranked under 6 groups based on the type and duration of activity and independent budget. These indicators (type, definition, selection criteria, data gathering procedures, and their weights) were regularly updated and revised based on the policies of the country's HRS and the feedback of stakeholders. The Expert Evaluation Committee included 7 experts on research, scientometrics, and representatives of UMSs, and MRCs recruited based on their expertise. Based on these indicators, all published articles of MRCs were extracted considering unique search strategy based on their affiliation from PubMed, ISI Web of Science, and Scopus databases, and evaluated and confirmed by research experts. After calculating the raw score, normalized score was computed based on indicator weight so that the highest score was considered the highest quantity in each indicator. For example, the highest number of 5-year citation was considered 400 and the score of the rest was calculated on this basis. Finally, considering the total score, MRCs were compared and ranked in each group.
The research indicators used to evaluate MRCs were as follow:

- Published articles: The number of each MRC published article indexed in scientific international databases, including ISI Web of Science, PubMed, and Scopus, according to its affiliation during 2015 to 2017 . The weight of this indicator is 250 . The number of papers indexed in PubMed, ISI Web of Science, and Scopus was multiplied by $2,1.5$, and 1 , respectively. Then, scoring was performed based on the indicator weight.

- Citations per published article: The total number of citations in the evaluation year to MRCs' published articles in the past 5 years based on the Scopus database. The maximum weight of this index is 400 .

- High quality publication (Q1): The number of each MRC published articles in $25 \%$ of the top journals in each category/area based on the SC imago Journal Ranking (SJR) index during 2015 to 2017 . This index was calculated with the weight of 250 .

- International cooperation (IC): The number of published papers resulting from international cooperation based on Scopus database during 2015 to 2017. The highest number of international cooperation receives the weight of 150 .

- H-Index: The h-index for total articles published by each MRC based on Scopus databases. The weight of this index is 100 .

In this study, to determine the research performance of SDHRCs, the research indicators of these centers were compared with MRCs and Iran's HRS. Also, SDHRCs were ranked based on their 3-year research performance extracted from MRCs evaluation reports with the same research indicators. In the present study, data analysis and scoring were done by SPSS version 21 considering descriptive statistics. Moreover, all ethical considerations were observed.

\section{Results}

Results are presented in 2 general sections. First, knowledge production of MRCs and Iran's HRS were presented, and all UMSs were reported based on research indicators (Table 1). Second, further details on ranking of SDHRCs were provided according to the international research indicators.

In this study, 33 out of 37 approved SDHRCs were investigated. Results showed that 29 out of the 56 Iranian UMSs had at least 1 SDHRC. These research centers did not have an independent budget and had at least 3 years of official experience. The oldest SDH research center was

Table 1. Comparison of research indicators between MRCs and HRS during 2015-2017

\begin{tabular}{lcccccc}
\hline & \multicolumn{3}{c}{ MRCs } & \multicolumn{3}{c}{ HRS (UMSs) } \\
\cline { 2 - 7 } Indicators & 2015 & 2016 & 2017 & 2015 & 2016 & 2017 \\
Published articles (N) & 15288 & 19772 & 22234 & 23174 & 30417 & 34623 \\
High quality publication (Q1) (N) & 2002 & 3438 & 4137 & 3068 & 4640 & 5716 \\
Q1/total published articles (\%) & 13.1 & 17.4 & 18.6 & 13.2 & 15.3 & 16.5 \\
Citations to 5 year published articles (N) & 63806 & 100414 & 148510 & 91929 & 145718 & 207155 \\
International cooperation (IC) (N) & 1964 & 2399 & 3779 & 2436 & 3544 & 5357 \\
IC/total published articles (\%) & 12.8 & 12,77 & 17 & 10.5 & 11.7 & 15.5 \\
\hline MRCs: Medical Research Centers. & & & & & &
\end{tabular}

RRS: Health Research Systent 


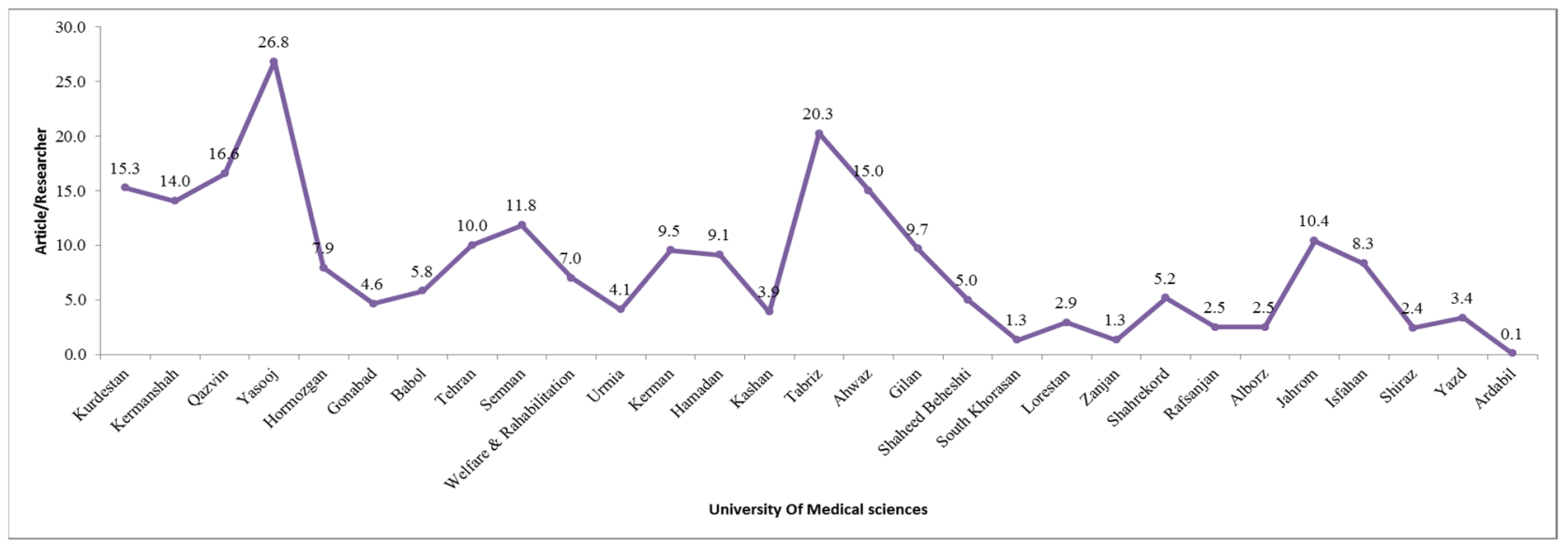

Fig. 2. Distribution of 3-year published articles per academic member in SDHRCs

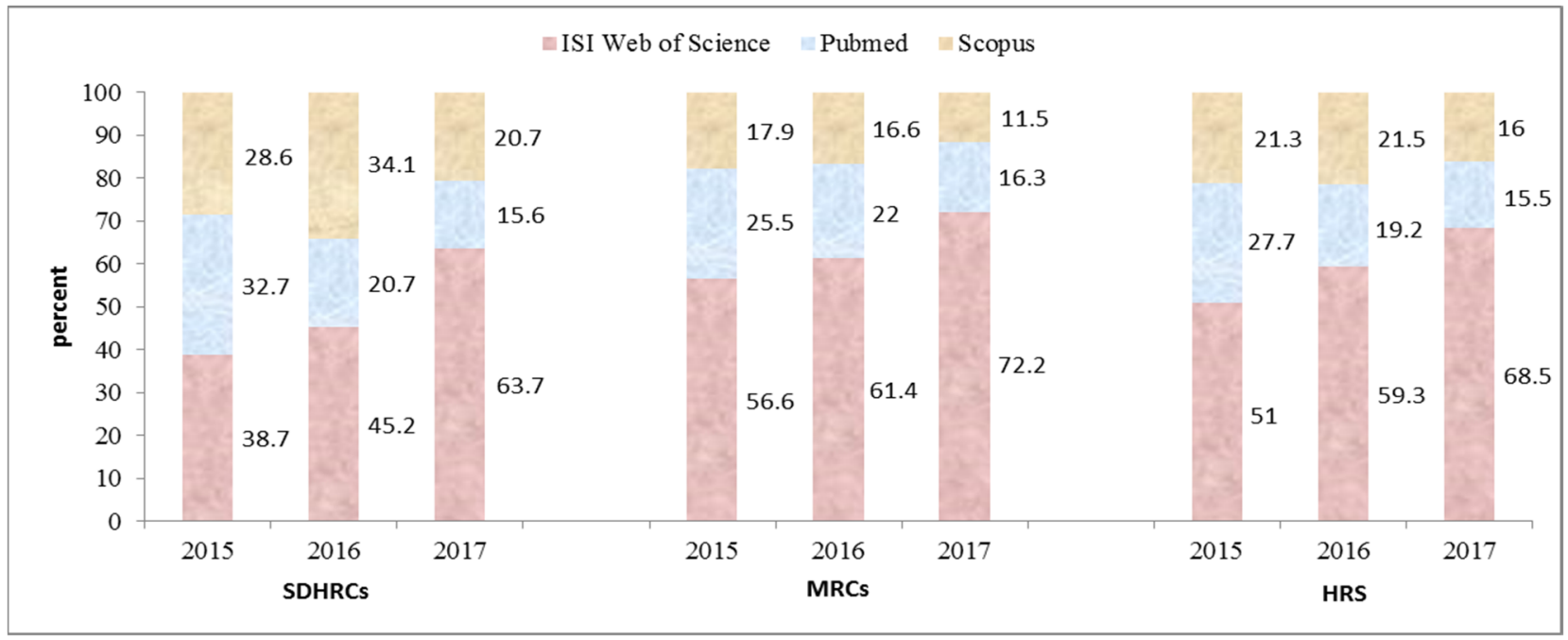

Fig. 3. The ratio of SDHRCs, MRCs, and HRS published articles in ISI Web of Science, PubMed, and Scopus in 2015,2016 and 2017

the Social Development and Health Promotion Research Center of Kermanshah UMS, which was approved in 2006.

Moreover, 334 academic members worked in these SDHRCs in 2017, with the highest number $(n=25)$ working in the SDHRC of South Khorasan UMS (Birjand). The mean ratio of academic members per research center was approximately 10 .

In the following, the results of research outputs of these centers are presented based on international research indicators from 2015 to 2017.

- Published articles: In general, 2370 papers were published by SDH research centers in ISI Web of Science, PubMed, and Scopus databases, comprising 483, 903, and 984 articles in 2015, 2016, and 2017, respectively. In that same period, the total published articles of the approved MRCs were 15 288, 19772 , and 22234 in the same databases. Among studied research centers, the SDHRC of Kurdistan UMS had the highest number of published articles $(n=244)$ in this 3 -year period. The proportion of published papers per academic member in the studied research centers was $1.44,2.7$, and 2.94 in 2015,2016 , and 2017 , respectively. This ratio was $1.35,1.75$, and 1.85 in Iran's HRS, respectively. Also, the mean ratio of 3-year published articles per academic member in SDHRCs was
$8.2(\operatorname{Max}=26.8$ Yasooj SDHRC and Min $=0.1$ Ardabil SDHRC) and 4.7 in HRS respectively. The distribution of SDHRCs' published articles per academic member in each UMS is presented in Figure 2.

Moreover, approximately $52 \%$ of all articles published by these research centers (1222) in the studied period were published in the ISI Web of Science. However, this ratio is $64.3 \%$ in other MRCs and $60.7 \%$ in Iran's HRS in the same period (Fig. 3).

- Citations to the published articles: From 2015 to 2017, the number of citations by the SDHRCs in the past 5 years was 4355 according to Scopus database. The SDHRC of Kermanshah UMS with 566 citations had the highest number of citations from among similar SDHRCs in the same period. The ratio of citations per published papers in SDHRCs was 1.8, meaning that each article has approximately been cited by 2 other published articles in the Scopus database. This ratio was 5.4 and 5 in MRCs and Iran's HRS, respectively. The ratio of citation per article in SDHRCs, MRCs, and HRS during 2015, 2016 and 2017 is presented in Figure 4.

- High quality publication: The total number of articles published by SDHRCs in the top $25 \%$ of journals of each field was 196 during 2015 to 2017, based on the SJR index. The SDHRC of Kurdistan UMS had the highest num- 


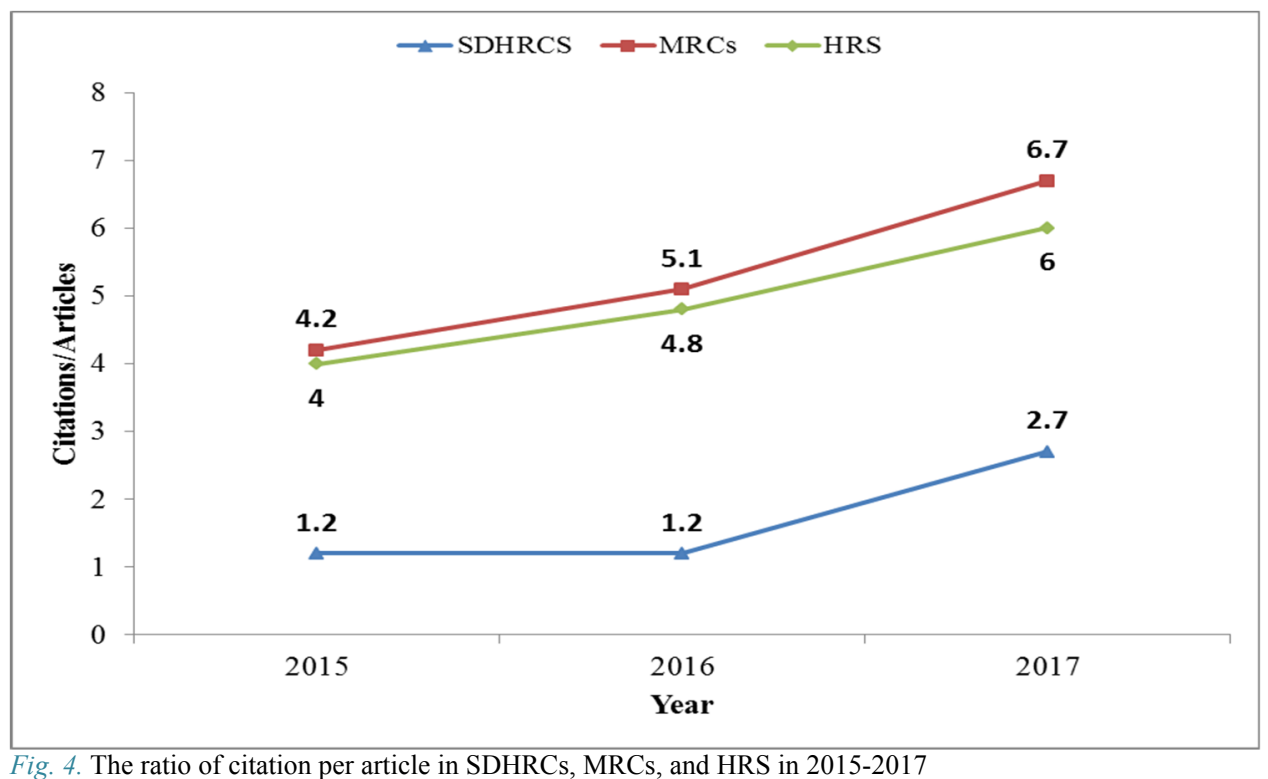

ber, with 36 papers published in Q1 journals (14.8\% of all articles published by this research center) in the mentioned period. Furthermore, the proportion of papers in Q1 journals per total published articles in SDHRCs was $8.4 \%$.

- International collaboration: Further and more detailed reviews indicated 202 articles published by SDHRCs in 2015 to 2017 have been the result of international collaboration. The proportion of papers resulted from international collaboration per SDHRCs total published articles in 2015, 2016, and 2017 was 7.2, 6.86, and 10.67, respectively. This ratio was $12.8,12.77$, and 17 in MRCs in the same period. From among the studied research centers, the SDHRC of Qazvin UMSs had the highest number of articles derived from international collaboration $(n=50)$, as more than $4 \%$ of papers published by this research center had at least 1 foreign collaborator.

- H-Index: From among the studied research centers, the SDHRC of Kermanshah UMSs had the highest h-index (18) based on Scopus database. The 3-year mean of hindex shows the superiority of this research center compared to others.

Table 2 shows the results of ranking SDHRCs based on mentioned international research indicators. In this table, all the indicators have been computed and ranked considering total 3-year knowledge production of SDHRCs. Based on this scoring system, the first to third ranks were occupied by SDHRCs of Kermanshah, Kurdistan, and Qazvin UMSs.

Furthermore, using descriptive analyses tests, no significant relationship existed between SDHRCs according to total score, number of academic members, and years of experience $(\mathrm{p}>0.05)$.

\section{Discussion}

Globally, evidence-based policymaking and interventions on SDH are seen as an effective response in tackling health equities. Describing the extent of the problem requires valid data and updated context-dependent evidence on social determinants and appropriate ways to reduce health inequalities (23). Thus, SDHRCs are specifically established to develop methods for evaluating the impact of population level interventions to reduce equities in different contexts through the combination of research activities such as multidisciplinary knowledge production and knowledge translation as the 2 main vital processes in taking social action on health equalities considering their ideological, political, and economic barriers and limitations (24).

Results showed that approved MRCs in the domain of SDH makes approximately 5\% of all approved MRCs in Iran. The number of SDHRCs has been tripled from 2011 to 2015. Although establishment of more SDHRCs has a significant role in expanding the research platform in this domain and is considered as a remarkable strategy by National Master Plan for Science and Education, it requires more infrastructures such as human and financial resources, especially in public health (17). Moreover, training and recruitment of social science researchers is seriously recommended. Also, more attention should be paid to facilitating the process of research grants and funding in universities. Nowadays, nationally, less than $0.5 \%$ of Iran's gross domestic product (GDP) is allocated to research and development (R\&D) expenditures, of which about $60 \%$ is used in the governmental sector and only $5 \%$ is allocated to health research (25).

Recently, knowledge production indicators in international institutional research rankings have attracted considerable attention worldwide. Several well-known ranking systems, such as Academic Ranking of World Universities (ARWU) (21), Times Higher Education (22), and Scimago Institutions Ranking (20), utilize different types of indicators to assess and evaluate the research processes such as knowledge productions.

Common indicators in this field consist of number of published articles (output), number of citations, international cooperation, etc. $(21,22)$. 


\begin{tabular}{|c|c|c|c|c|c|c|c|c|c|c|c|c|c|c|c|}
\hline Rank & $\begin{array}{l}\text { University of } \\
\text { Medical } \\
\text { Sciences } \\
\end{array}$ & $\begin{array}{l}\text { Research } \\
\text { Center }\end{array}$ & $\begin{array}{l}\text { Researchers } \\
\text { (N) }\end{array}$ & $\begin{array}{c}\text { Date } \\
\text { Approved }\end{array}$ & $\begin{array}{l}\text { Article } \\
(\mathrm{N})\end{array}$ & $\begin{array}{l}\text { AS* of } \\
\text { Output }\end{array}$ & $\begin{array}{l}\text { Q1 Articles } \\
\text { (N) }\end{array}$ & $\begin{array}{c}\text { AS of Q1 } \\
\text { Articles }\end{array}$ & $\begin{array}{l}\text { IC Arti- } \\
\text { cles }(\mathrm{N})\end{array}$ & $\begin{array}{l}\text { AS of IC } \\
\text { Articles }\end{array}$ & $\begin{array}{l}\text { Citations } \\
(\mathrm{N})\end{array}$ & $\begin{array}{c}\text { AS of } \\
\text { Citations }\end{array}$ & $\begin{array}{l}\text { Average h } \\
\text { index }\end{array}$ & $\begin{array}{l}\text { AS of h } \\
\text { index Score }\end{array}$ & $\begin{array}{l}\text { Total } \\
\text { Score }\end{array}$ \\
\hline 1 & Kermanshah & SDH & 12 & 2013 & 224 & 229.51 & 13 & 72.22 & 24 & 72 & 566 & 400.00 & 11.3 & 100.00 & 873.73 \\
\hline 2 & Kurdistan & $\mathrm{SDH}^{* *}$ & 16 & 2011 & 244 & 250.00 & 36 & 200.00 & 20 & 60 & 391 & 276.33 & 7.3 & 64.60 & 850.93 \\
\hline 3 & Qazvin & SDH & 7 & 2011 & 116 & 118.85 & 20 & 111.11 & 50 & 150 & 284 & 200.71 & 9 & 79.65 & 660.32 \\
\hline 4 & Yasooj & SDH & 6 & 2010 & 161 & 164.96 & 15 & 83.33 & 7 & 21 & 332 & 234.63 & 9 & 79.65 & 583.57 \\
\hline 5 & Hormozgan & SDH & 18 & 2009 & 143 & 146.52 & 4 & 22.22 & 6 & 18 & 290 & 204.95 & 6.6 & 58.41 & 450.1 \\
\hline 6 & Gonabad & $\mathrm{SD} \& \mathrm{HP}^{* * * *}$ & 19 & 2009 & 100 & 102.46 & 9 & 50.00 & 2 & 6 & 256 & 180.92 & 6.6 & 58.41 & 397.79 \\
\hline 7 & Babol & SDH & 20 & 2012 & 116 & 118.85 & 11 & 61.11 & 3 & 9 & 210 & 148.41 & 6.6 & 58.41 & 395.78 \\
\hline 8 & Semnan & SDH & 12 & 2013 & 142 & 145.49 & 4 & 22.22 & 5 & 15 & 203 & 143.46 & 6.3 & 55.75 & 381.92 \\
\hline 9 & Tehran & $\mathrm{CBPR}^{* * * * *}$ & 6 & 2008 & 60 & 61.48 & 11 & 61.11 & 8 & 24 & 214 & 151.24 & 8.3 & 73.45 & 371.28 \\
\hline 10 & Kermanshah & SD \& HP & 11 & 2006 & 99 & 101.43 & 1 & 5.56 & 8 & 24 & 214 & 151.24 & 10 & 88.50 & 370.73 \\
\hline 11 & $\begin{array}{c}\text { Welfare \& } \\
\text { Rehabilitation }\end{array}$ & SDH & 11 & 2009 & 77 & 78.89 & 4 & 22.22 & 11 & 33 & 173 & 122.26 & 8.3 & 73.45 & 329.82 \\
\hline 12 & Kerman & SDH & 12 & 2012 & 92 & 94.26 & 3 & 16.67 & 5 & 15 & 143 & 101.06 & 5.3 & 46.90 & 273.89 \\
\hline 13 & Hamadan & SDH & 8 & 2013 & 73 & 74.80 & 6 & 33.33 & 5 & 15 & 127 & 89.75 & 6.3 & 55.75 & 268.63 \\
\hline 14 & Urmia & SDH & 10 & 2013 & 41 & 42.01 & 10 & 55.56 & 6 & 18 & 141 & 99.65 & 6 & 53.10 & 268.32 \\
\hline 15 & Kashan & SDH & 10 & 2013 & 39 & 39.96 & 5 & 27.78 & 3 & 9 & 130 & 91.87 & 6.6 & 58.41 & 227.02 \\
\hline 16 & Tabriz & SDH & 4 & 2012 & 81 & 82.99 & 9 & 50.00 & 1 & 3 & 44 & 31.10 & 3.6 & 31.86 & 198.95 \\
\hline 17 & Ahwaz & SDH & 5 & 2012 & 75 & 76.84 & 3 & 16.67 & 5 & 15 & 53 & 37.46 & 4 & 35.40 & 181.37 \\
\hline 18 & Gilan & SDH & 6 & 2012 & 58 & 59.43 & 3 & 16.67 & 2 & 6 & 73 & 51.59 & 4.3 & 38.05 & 171.74 \\
\hline 19 & $\begin{array}{l}\text { Shaheed } \\
\text { Beheshti }\end{array}$ & SDH & 5 & 2012 & 25 & 25.61 & 6 & 33.33 & 8 & 24 & 59 & 41.70 & 3.6 & 31.86 & 156.5 \\
\hline 20 & $\begin{array}{c}\text { South } \\
\text { Khorasan }\end{array}$ & SDH & 25 & 2013 & 33 & 33.81 & 0 & 0 & 2 & 6 & 90 & 63.60 & 5.6 & 49.56 & 152.97 \\
\hline 21 & Zanjan & SDH & 22 & 2012 & 29 & 29.71 & 7 & 38.89 & 3 & 9 & 26 & 18.37 & 3 & 26.55 & 122.52 \\
\hline 22 & Lorestan & SDH & 15 & 2012 & 44 & 45.08 & 6 & 33.33 & 3 & 9 & 18 & 12.72 & 2.3 & 20.35 & 120.48 \\
\hline 23 & Shahrekord & SDH & 6 & 2012 & 31 & 31.76 & 1 & 5.56 & 3 & 9 & 46 & 32.51 & 4 & 35.40 & 114.23 \\
\hline 24 & Rafsanjan & SDH & 6 & 2012 & 15 & 15.37 & 3 & 16.67 & 2 & 6 & 46 & 32.51 & 4.3 & 38.05 & 108.6 \\
\hline 25 & Kerman & $\begin{array}{c}\text { SD of } \\
\mathrm{DH}^{* * * * * *}\end{array}$ & 5 & 2013 & 70 & 71.72 & 1 & 5.56 & 1 & 3 & 17 & 12.01 & 1.6 & 14.16 & 106.45 \\
\hline 26 & Gonabad & SDH & 8 & 2012 & 25 & 25.61 & 0 & 0.00 & 2 & 6 & 59 & 41.70 & 3.3 & 29.20 & 102.51 \\
\hline 27 & Alborz & SDH & 10 & 2012 & 25 & 25.61 & 1 & 5.56 & 3 & 9 & 35 & 24.73 & 3 & 26.55 & 91.45 \\
\hline 28 & Jahrom & SDH & 5 & 2013 & 52 & 53.28 & 0 & 0.00 & 2 & 6 & 24 & 16.96 & 1.6 & 14.16 & 90.4 \\
\hline 29 & Isfahan & SDH & 3 & 2011 & 25 & 25.61 & 0 & 0.00 & 0 & 0 & 42 & 29.68 & 3 & 26.55 & 81.84 \\
\hline 30 & Shiraz & SDH & 7 & 2012 & 17 & 17.42 & 1 & 5.56 & 0 & 0 & 31 & 21.91 & 3.6 & 31.86 & 76.75 \\
\hline 31 & Yazd & SDH & 4 & 2010 & 26 & 26.64 & 2 & 11.11 & 1 & 3 & 16 & 11.31 & 2.6 & 23.01 & 75.07 \\
\hline 32 & Yazd & SD of DH & 7 & 2011 & 11 & 11.27 & 0 & 0.00 & 0 & 0 & 1 & 0.71 & 0.6 & 5.31 & 17.29 \\
\hline 33 & Ardabil & SDH & 13 & 2012 & 1 & 1.02 & 1 & 5.56 & 1 & 3 & 1 & 0.71 & 0.6 & 5.31 & 15.6 \\
\hline
\end{tabular}

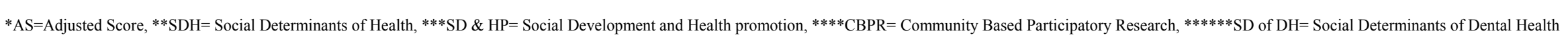


Based on the results of this study, during 2015 to 2017 , MRCs have published 57294 research articles (taking into account collaborated papers). About $4 \%$ of these scientific articles have been published by SDHRCs, although the number of published articles has been doubled in this period. Also, comparison of the mean ratio of SDHRCs' 3-year published articles per academic members to Iran's HRS reveals that researchers and academic members in these research centers publish articles 4 times more than other academic members in Iranian UMSs. On average, each SDHRC's academic member has been involved in at least 7 articles, compared to 4 articles in HRS during these years.

This matter has certain advantages and disadvantages. The major advantage is the involvement of SDHRCs researchers with knowledge production, and this is consistent with the Measurement and Evidence Knowledge Network of WHO Commission Social Determinates of Health advice, which is essential to develop evidence based on SDH and health inequities (25). Much more important than describing social injustice, SDHRCs must participate in knowledge translation to move research into policy and provide community-based evidence for policymaking to promote health equity (26). There is evidence that demonstrates the importance of science in the development of actions and policies in reducing health inequities (24).

During 2015-2017, approximately 8\% of SDHRCs' scientific articles were published in the top $25 \%$ of journals (Q1) in their respective majors, while this percentage was $16.7 \%$ in other MRCS and $15 \%$ in Iran's HSR in those 3 years, respectively. Although there are fewer Q1 journals related to $\mathrm{SDH}$ and health equity than other majors considering the SJR index (27), researchers in these centers must try to enhance the quality of their published papers.

Results of this study indicated that regardless of the increasing trend of the number of citations per published paper from 1.2 in 2015 to 2.7 in 2017 in SDHRCs, this proportion is still lower than Iran's HRS. The number of citations is considered as an representative index for article's quality and application $(28,29)$, although national policies, goals, and strategies in health research have direct impacts on its quantity (30). Nevertheless, based on the main mission of these research centers to generate appropriate evidence to have impact on equity, it was impossible to examine equity in this study, and further mixed method studies can investigate this topic.

The ratio of international cooperation in the studied research centers constituted only $8 \%$ of the SDHRCs total published papers, which is much less than this ratio in MRCs. Evidently, cooperation with other research centers active in this domain around the world can offer valuable experience to the researchers in these centers. Also, SDHRCs are new in Iran, and thus it is necessary to provide the essential infrastructure, such as research allocation and strengthening the capacity on research in major concepts regarding SDH, health equity, and relevant indices (5). Tackling health inequities needs more community-based research and actionable policies, where nonscholarly intersectoral cooperation related or nonrelat- ed to health organizations can assist the researchers to achieve the best actionable evidence.

Considering the guidelines and recommendations provided by the CSDH of WHO, the major mission of these SDHRCs must generate knowledge and evidence to promote health equity, distribute equitable intermediate social determinants, and modify actionable policymaking in terms of structural social determinants (31). Thus, one of the limitations of this study was focusing on the knowledge production in these research centers and neglecting knowledge translation indicators. Other weaknesses were the presence of different types of affiliations applied by SDHRCs' academic members that caused disruptions in access to published documents in mentioned databases. In addition, there was lack of attention in SDHRCs' research input indicators, such as budget, human resources, research projects, and other infrastructures reflecting their potential research capabilities.

\section{Conclusion}

Due to the lack of scientific evidence regarding SDH fields, it is essential to set the national priorities through stakeholders' cooperation and plan mission-based strategies. Moreover, creating a virtual research network can complete the existing challenges in the puzzle of evidence on the social determinants of health.

\section{Acknowledgements}

The authors wish to thank the Research Experts at the Deputy of Research and Technology- Ministry of Health and Medical Education- and universities of medical sciences for their assistance with data collection and review.

\section{Conflict of Interests}

The authors declare that they have no competing interests.

\section{References}

1. Carey G, Crammond B. Action on the social determinants of health: views from inside the policy process. Soc Sci Med. 2015;128:134141.

2. Plamondon KM, Bottorf JL, Susana Caxaj C, Graham ID. The integration of evidence from the Commission on Social Determinants of Health in the field of health equity: a scoping review. Crit Public Health. 2018:1-14.

3. Eckersley R. Beyond inequality: Acknowledging the complexity of social determinants of health. Soc Sci Med. 2015;147:121-125.

4. Donkin A, Goldplatt P, Allen J, Nathanson V, Marmot M. Global action on the social determinants of health. BMJ Glob Health. 2018;3(Suppl 1).

5. Henschke N, Mirny A, Haafkens J, Ramroth H, Padmowati S, Bangha $\mathrm{M}$, et al. Strengthening capacity to research the social determinants of health in low-and middle-income countries: lessons from the INTREC programme. BMC Public Health. 2017;17(1):514

6. WHO Commission of Social Determinants of Health. Closing the gap in a generation: health equity through action on the social determinants of health: final report of the commission on social determinants of health. 2008.

7. Solar O, Irwin A. A conceptual framework for action on the social determinants of health. WHO Commission on Social Determinants of Health 2007.

8. Marmot M, Allen JJ. Social determinants of health equity. 2014, Am Public Health Association.

9. WHO Commission of Social Determinants of Health Closing the gap in a generation: health equity through action on the social 
determinants of health: Commission on Social Determinants of Health final report. 2008: World Health Organization.

10. Marmot M, Allen J, Bell R, Bloomer E, Goldblatt P. WHO European review of social determinants of health and the health divide. Lancet. 2012;380(9846):1011-1029.

11. Mnistry of Health and MEdical Education - Health policy Secretariat. 2005 [cited 2019 29/1/2019]; Available from: http://selection.behdasht.gov.ir/index.aspx?siteid=331.

12. Social Determinants of Health. 2010 [cited 2019 25/1/2019]; Available from: http://sdh.behdasht.gov.ir/index.aspx?siteid=331\&f keyid $=$ \&siteid $=331$ \&pageid $=34213$.

13. Zaboli R, Sanaeinasab H. The Challenges and Solutions for Action of Social Determinants of Health in Iran: A Qualitative Study. Iran J Health Educ Health Promot. 2014;2(1):5-16.

14. Deputy of Research and Technology. The list of Approved Medical Research Centers. 2019 [cited 2019 25/1/2019]; Available from: http://hbi.ir/Part1/Unit.aspx?hbsId=145\&category=1\&templateid=1\& hdlId $=22$.

15. Deputy of Research and Technology. The Evaluation of Research performance of Medical Research Centers. 2019 [cited 2019 25/1/2019]; Available from: http://hbi.ir/part1/Unit.aspx?hbsId=105\& category $=1$ \& templateid $=1 \&$ hdlId $=4$.

16. Bahadori M, Sanaeinasab H, Ghanei M, Mehrabi Tavana A, Ravangard R, et al. The Social Determinants of Health (SDH) in Iran: A Systematic Review Article. Iran J Public Health. 2015;44(6):728.

17. Eftekhari MB, Falahat K, Ebadifar A, Eltemasi M, Sobhani Z, Ghalenoee E, et al. The Role of Medical Research Centers in Health Research System Promotion in IR of Iran: 2001-2014. Arch Iran Med. 2017;20(11).

18. Falahat K, Eftekhari MB, Habibi E, Djalalinia Sh, Peykari N, Owlia $\mathrm{P}$, et al. Trend of knowledge production of research centers in the field of medical sciences in Iran. Iran $J$ Public Health. 2013;42(Supple1):55.

19. Eftekhari MB, Sobhani Z, Eltemasi M, Ghalenoee E, Falahat K, Habibi E, et al. Research Ranking of Iranian Universities of Medical Sciences Based on International Indicators: An Experience From IR of Iran. Arch Iran Med. 2017;20(11):673.

20. Bornmann L, de Moya-Anegón F, Leydesdorff L. The new excellence indicator in the World Report of the SCImago Institutions Rankings. J Informetr. 2011;6(2):333.

21. Cheng Y. Academic ranking of world universities (ARWU) by subjects and fields: Methodologies, challenges and future plans. Subject and Discipline Related Rankings-a More Inclusive Approach to University Performance (IREG 2015), IREG Observatory on Academic Ranking and Excellence, 2015.

22. Stack ML. The Times Higher Education ranking product: Visualising excellence through media. Global Societ Educ. 2013;11(4):560-582.

23. Fouad MN, Oates GR, Scrinci IC, Wahnefried WD, Hamby BW, Beteman LB, et al. Advancing the science of health disparities through research on the social determinants of health. Am J Pre Med. 2017;52(1):S1-S4.

24. Muntaner C, Chung H, Murrphy K, Ng E. Barriers to knowledge production, knowledge translation, and urban health policy change: ideological, economic, and political considerations. J Urban Health. 2012;89(6):915-924.

25. Bambra C, Gibson M, Sowden A, Wright K, Whitehead M, Petticrew M. Tackling the wider social determinants of health and health inequalities: evidence from systematic reviews. J Epidemiol Commun Health, 2010. 64(4): p. 284-291.

26. Masuda JR, Zupancic T, Crighton E, Muhajarine N, Phipps E. Equity-focused knowledge translation: a framework for "reasonable action" on health inequities. Int J Public Health. 2014;59(3):457-464.

27. SJR. Scimago Journal nd Country Rank. 2018; Available from: https://www.scimagojr.com/journalrank.php?type $=\mathrm{j}$.

28. Djalalinia SH, Peykari N, Eftekhari MB, Sobhani Z, Laali R, Gorbani OA, et al. Contribution of health researches in national knowledge production: A scientometrics study on 15 -year research products of Iran. Int J Prevent Med. 2017;8.

29. Djalalinia SH, Peykari N, Owlia P, Eftekhari MB, Habibi E, Falahat $\mathrm{K}$, et al. The analysis of health research system evaluation in medical sciences universities. Iran J Public Health. 2013;42(Supple1):60.

30. Larijani MB, Majdzadh R, Delavari AR, Rajabi F, Khattbzadeh S, Esmailzadeh $\mathrm{H}$, et al. Iran's health innovation and science development plan by 2025. Iran J Public Health. 2009;38(1):13-16.
31. Smith J, Griffiths K, Judd J, Crawford G, D`Antoine H, Fisher M, et al. Ten years on from the world health organization commission of social determinants of health: Progress or procrastination? Health Promot J Austr. 2018;29(1):3. 